\title{
NÍVEL DE CULPABILIDADE EM ADOLESCENTES EM CONFLITO COM A LEI
}

\author{
LEVEL OFADOLESCENT CULPABILITY IN CONFLICT WITH THE LAW
}

\begin{abstract}
Amanda Gleiciane de Lima Oliveira', Landerson Carlos Martins de Souza', Tainá Maia Barros ${ }^{1}$, Palloma Linhares Medeiros' ${ }^{1}$, Thatiane Maria Barboza da Silveira Batista1, Ismael Ferreira da Costa², Camila Yamaoka Mariz Maia ${ }^{3}$
\end{abstract}

RECEBIDO EM: 11/11/2018 | ACEITO EM: 12/03/2019

DOI: $10.5902 / 2317175832516$

\section{RESUMO}

Problemáticas voltadas ao adolescente autor de ato infracional são bastante recorrentes. Questões como perspectivas de vida, motivações e eficácia de medidas são deveras discutidas. Em uma nova perspectiva, contudo, o presente artigo objetiva esclarecer acerca do nível de culpabilidade desses jovens internos da medida prevista no $121^{\circ}$ artigo do Estatuto da Criança e do adolescente. Para tanto utilizou-se de uma pesquisa de campo, descritiva, correlacional e quantitativa baseada na ESCA (Escala de Culpa Para Adolescentes) e em respostas proporcionadas por 80 internos. A partir das respostas obtidas e das análises estatísticas realizadas contatou-se uma forte ascensão positiva nos escores, dessa forma apresentando um alto nível de culpabilidade nos entrevistados e divergindo da literatura consulta.

Palavras chave: Adolescente; Culpa; Adolescente Institucionalizado

\footnotetext{
1 Estudantes do curso de Psicologia do Unipê-Centro Universitário.

2 Graduado em Psicologia pelo Centro Universitário de João Pessoa (UNIPÊ), Mestre em Neurociência Cognitiva e Comportamento pelo Programa de Pós-graduação em Neurociência Cognitiva e Comportamento da Universidade Federal da Paraíba (UFPB). Professor do departamento de psicologia no Centro Universitário de João Pessoa e pesquisador colaborador no Laboratório de Pesquisa em Cognição e Comportamento (LAPECC/UFPB). 3 Possui graduação em Psicologia pela Universidade Federal da Paraíba (2003), especialização em Psicologia Juridica pela Unidade de Ensino e Pesquisa em Psicologia e Psicanálise - UNEPSI (2005) e mestrado em Psicologia (Psicologia Social) pela Universidade Federal da Paraíba (2008). Atualmente é professora a do UNIPÊ e do IESP.
} 


\begin{abstract}
Issues related to the adolescent causer of an infraction are quite recurrent. Issues such as life prospects, motivations and effectiveness of measures are very much discussed. In a new perspective, however, this article aims to clarify the level of culpability of these young sentenced the measure foreseen in the 121 st article of the Statute of the Child and the adolescent. For this purpose, used descriptive, correlational and quantitative research based on ESCA (Scale of Guilt for Adolescents) and responses provided by 80 young transgressors. From the answers obtained and from the statistical analyzes performed, a strong positive rise in scores was observed, thus presenting a high level of culpability among the interviewed minors and diverging from the literature consulted.
\end{abstract}

Keywords: Adolescent; Guilt; Adolescent, Institutionalized

\title{
1 Introdução
}

O período da adolescência carrega por si só uma pressão advinda da passagem intelectual para a independência moral e realista além um leque de mudanças biopsicossociais características dessa fase. Pertinente a esta fase são atribuídos uma série de comportamentos de risco particulares como a promiscuidade sexual desprotegida e as manifestações agressivas (PROENÇA, 2018).

Há várias vertentes no campo da psicologia do desenvolvimento que atribuem a adolescência, além de diversas transformações, o marco do amadurecimento e a instabilidade da consciência moral, onde um dos pilares da moralidade é o arrependimento, remorso ou culpabilidade. A culpa, por sua vez, seria proveniente de uma perversidade ocasionado a outrem (LIMA et al, 2015). Este sentimento que assola a maioria dos seres humanos intriga e dispõe do interesse das várias abordagens da psicologia desde a Psicanálise ao behaviorismo (WINNICOTT, 1983; GUILHARDE, 2002)

Logo, o presente artigo busca esclarecer a relação entre punição e culpabilidade aplicando estes conceitos aos internos da medida prevista no $121^{\circ}$ artigo do Estatuto da Criança e do adolescente, a privação de liberdade devida a ato infracional à luz da Psicologia Jurídica e Psicologia Social fazendo paralelos em alguns momentos com a abordagem Psicanálitica e a Terapia Cognitivo-Comportamental. Deste modo valeu-se de uma Pesquisa de Campo, Quantitativa, Descritiva e Correlacional fixada em uma instituição socioeducativa, na cidade de João Pessoa, com emprego de entrevistas baseadas na Escala de Culpabilidade Para Adolescentes posteriormente analisadas pelo pacote estático SPSS 20.0, afim de elucidar a problemática: Qual o nível de culpabilidade de adolescentes autores de atos infracionais?

Para maior compreensão acerca do tema seguem as seções: Revisão literária, Método, Resultados, Discussões e Considerações Finais. 


\section{Revisão Literária}

\subsection{0 período do pós-púbere}

O jovem como uma pessoa de natureza imprevisível, impulsiva, apaixonada e com pouca capacidade para retardar a gratificação ou tolerar a crítica (CAMPOS, 1986). Adolescentes e seus conflitos foram também retratados pela arte, como por exemplo, Shakespeare que trouxe alguns momentos desta etapa da vida em suas obras Hamlet e Romeu e Julieta.

Alguns admitem limites aproximados para a adolescência. Jones e Holmes localizam o período da adolescência entre 12 e 18 anos. Para aqueles que definem o início da puberdade é o ponto final das mudanças fisiológicas que começam aos 10 anos e meio; e o início da adolescência se dá, portanto, a partir daí (...) Hurlock prefere considerar o atingimento da maturidade legal aos 21 anos... Gesell e Hall colocam o fim da adolescência no início dos vinte e Pederson sugerem 25 anos como a idade em que 0 adolescente geralmente passa para a fase adulta (CAMPOS, 1986 p. 13,14).

Há concordância entre os autores quando se fala que o período que compreende a adolescência é rico em divergências tanto intra como interpessoais, pois assim como os primeiros anos de vida também se trata de um tempo fundamental de desenvolvimento. A adolescência, portanto, trata-se de uma gama de movimentos biopsicossociais na vida do indivíduo (IRWIN; MILLSTEIN 1986).

Logo é visto que a juventude é uma fase do desenvolvimento humano caracterizada pela transição em termos biológicos, psicológicos e sociais em que o adolescente se encontra com conflitos internos e externos, há uma constante busca de identidade, os vínculos deixam de ser centrados nas famílias e passam a ser enfatizados no desenvolvimento de relações sociais, neste contexto os jovens se encontram vulneráveis. Existem vários motivos para o envolvimento de adolescentes e os conflitos com a lei, Shoemaker (1996 apud FEIJÓ; ASSIS, 2004) conceitua três níveis:

O primeiro é o nível estrutural que atribui as infrações a fatores pessoas e situacionais. A maioria dos adolescentes entraria em conflito com a lei como forma de sobrevier ou aumentar a renda familiar. A desorganização social existente nas instituições e estruturas da sociedade levam o jovem a cometer atos infracionais. O segundo é o nível individual que classifica os mecanismos internos dos indivíduos como características determinantes para comportamentos do infrator em seus aspectos biológicos e psicológicos. O terceiro e último é o nível sócio psicológico, nesse nível, o jovem quebra seus vínculos com as instituições responsáveis por seu controle. O infrator sofre influência da sua autoestima e de grupos de adolescentes (SHOEMAKER,1996 apud FEIJÓ; ASSIS, 2004). 
O Estatuto da Criança e do Adolescente de 2002 descreve uma série de medidas socioeducativas no Art. 112, desde advertência a internação. Logo, quando se verifica a veracidade de um ato infracional a gravidade deste ato designa legalmente a punição a ser aplicada. No $115^{\circ}$ artigo é colocada a medida mais leve a ser aplicada, a secção da advertência, o Art. 116 referente a reparação do dano, no $117^{\circ}$ artigo se descreve a IV secção, relacionada a prestação de serviços à comunidade, na quarta medida apresentada pelo ECA no Art. 118 surge a liberdade assistida, a secção VI, artigo Art. 120 prediz o regime de semiliberdade e atenta para que este pode ser designado desde o início ou meio alternativa para a medida do $121^{\circ}$ artigo (Lei $n^{\circ} 8.069$, de 13 de julho de 1990).

A medida de privação de liberdade é a designada a crimes com alto nível de gravidade e está prevista no $121^{\circ}$ artigo, o adolescente deve cumprir medida socioeducativa de privação de no mínimo seis meses a no máximo três anos, podendo ser reduzida, estendida e alterada se assim se dever, deve-se atentar também que esta medida em hipótese alguma deve ter adotada se houver a possibilidade de utilizar medidas mais leves sendo ela usada somente em última instancia. O local necessita ainda proporcionar um ambiente de respeito ao adolescente visando a saúde de seu desenvolvimento (Lei $n^{\circ} 8.069$, de 13 de julho de 1990).

Entendendo as medidas socioeducativas parte-se para o princípio da reincidência, uma vez que há a dúvida persistente acerca da eficácia das ações punitivas. Há a ocorrência do não cumprimento das medidas de socialização, de profissionalização e de reabilitação educacional o que por sua vez gera a maior possibilidade de reincidência logo porque não se tem outras visões (SÁ, 2009).

Conforme dados estatísticos obtidos junto a Vara da Infância a da juventude do Tribunal de Justiça do Distrito Federal e Territórios as medidas que mais contabilizam reincidência são prestação de serviços à comunidade e a internação, indo contra a concepção do senso comum sendo que se tem a ideia de que quanto mais rigorosa a punição mais eficaz a reeducação. A reincidência abre discussão junto a culpabilidade uma vez que o intuito de ambos os termos seria, ao menos teoricamente, a não repetição do ato, assim se tem juízo que nenhum dos dois se fizeram benéficos (BRASíLIA, 2016).

\subsection{O Desenvlvimento Moral e a Culpabilidade}

A teoria da psicanalise sobre desenvolvimento moral diz que a personalidade se divide em três partes, o ID, encarregado da energia psíquica, o Ego, coordena o equilíbrio entre as exigências do ID, as exigências da realidade e as 'ordens' do Superego e o Superego referente ás proibições dos limites e da autoridade, com isso o superego introduz a ideia do sentimento de culpa (FREUD, 1923 apud LAPSLEY, 2011). Segundo Bock; Furtado; Teixeira (2001), jovens em conflito com a lei não processam esse sentimento de culpa, por não julgarem errado e não ter uma figura de autoridade a qual o superego vá habilitar a função de algoz. 
As teorias cognitivas consideram o desenvolvimento pró-social como um processo cognitivo associado à capacidade do indivíduo de sentir empático com os outros e de descentralizar de si mesmo. De acordo com Kohlberg 1969 (apud KOLLER; BERNARDES, 1997), jovens em conflito com a lei não tem esse entendimento de ser empático, os teóricos dessa área, desprendem pouco significado as questões de como o ambiente influencia nesse quesito e focam mais nas questões inatas do indivíduo, em sua pré-disposição.

Um item importante no constructo moral do adolescente em geral é o sentimento de culpa ou culpabilidade. Na visão psicológica, psiquiátrica, psicanalítica e de Santos (2009) "a culpa envolve uma avaliação negativa de um comportamento específico", logo o sentimento de culpa está associado de forma intrínseca a auto avaliação e a percepção de si mesmo o chamado "self avaliativo".

Outro fator que pode funcionar como regulador da culpa é a aceitabilidade social, quando o erro recebe o peso de sansões espontâneas gera consequências como o afastamento de pessoas queridas, a exclusão de grupos ou classes e a perda de confiança. Esse fator pode influenciar na magnitude da culpabilidade, quando essas sansões espontâneas afetam diretamente a qualidade de vida do indivíduo e o seu bem estar social.Assim para a visão analítico comportamental a culpa se daria na forma do reconhecimento de um comportamento inadequado a partir das justificações aversivas de outros indivíduos, o que geraria dessa forma a diminuição na taxa desse comportamento. (GUILHARDI, 2002).

\section{Método}

Efetuou-se dessa forma uma pesquisa de campo descritiva, quantitativa e de delineamento correlacional, (SHAUGHNESSY; ZECHMEISTER; ZECHMEISTER, 2012), aprovada pelo comitê de ética protocolo 57784816.7.000.5176. A pesquisa então realizou-se no Centro Socioeducativo Edson Mota (CSE), em João Pessoa, A técnica de amostragem deliberada foi a não probabilística por conveniência, o que possibilitou a colaboração de 80 internos do CSE com idades entre 13 e 17 anos, todos do sexo masculino devido ao universo ser composto unicamente por tal.

O procedimento de coleta de dados se deu por meio de entrevista individual com cada participante onde foram esclarecidos os pareceres éticos segundo a Resolução n 466/12 e a Resolução n. 510/16 do ministério da saúde e os direitos de desistência e anonimato quanto a divulgação dos dados coletados (MINISTÉRIO DA SAÚDE, 2013).

As questões objetivaram verificar o nível de culpabilidade em adolescentes cumprindo medida socioeducativa de privação de liberdade, afim, de da mesma forma, verificar incidência de idade, escolaridade, estado civil e reincidência entre a amostra. Para a aferição dos dados valeu-se de uma escala sócio demográfica, de autoria própria, e uma escala especifica destinada 
ao construto principal. A escala utilizada foi a ESCA ou Escala de Culpa para adolescentes, desenvolvida e validada por Lorena Laskoski baseada ainda nos trabalhos de Tiago Aquino para a análise dos dados utilizou-se o pacote estatístico SPSS em sua versão 20.0.

\section{Resultados}

A partir dos dados analisados com base no questionário sociodemográfico acerca das condições presentes dos adolescentes da amostra, obtiveramse os seguintes resultados quantificados e distribuídos na Tabela 1, a seguir:

Tabela 1 - Frequências das Variáveis Sociodemográficas Relativas aos Adolescentes

\begin{tabular}{lll}
\hline $\begin{array}{l}\text { Variáveis } \\
\text { Idade }\end{array}$ & $\mathbf{N}^{\circ}$ & $\%$ \\
13 & 1 & $1,3 \%$ \\
14 & 2 & $2,5 \%$ \\
15 & 16 & $20,0 \%$ \\
16 & 25 & $31,3 \%$ \\
17 & 36 & $45,0 \%$ \\
Média & 16,16 & \\
Nível de Escolaridade & & \\
Sem Estudo & 5 & $7,5 \%$ \\
Ensino Fundamental Incompleto & 67 & $83,8 \%$ \\
Ensino Fundamental Completo & 2 & $2,5 \%$ \\
Ensino Médio Incompleto & 4 & $5,0 \%$ \\
Ensino Médio Completo & 1 & $1,3 \%$ \\
Estado Civil & & \\
Solteiro & 49 & $61,3 \%$ \\
Casado & 11 & $13,8 \%$ \\
Comprometido & 20 & $25,0 \%$ \\
\end{tabular}

Fonte: Elaboração Própria

A Tabela 1 desta forma elucida a média de idade dos consultados correspondente a aproximadamente 16 anos, onde o percentil maior encontrado se deus nos entrevistados de 17 anos, com 36 indivíduos indicando $45 \%$ da amostra. É perceptível também a uniformização dos dados enquanto a escolaridade, visto que a grande maioria, 67 jovens correspondendo a $83 \%$ da amostra, não concluiu o Ensino fundamental. É visto também que a maioria é solteira compondo $63 \%$ do total da amostra. Em relação a Reincidência pode-se notar: 
Grafico 1: Reincidencia

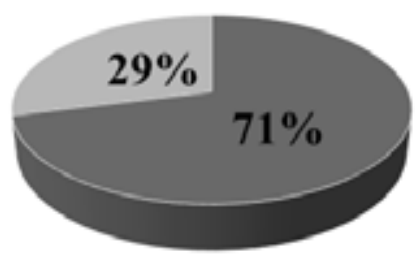

\section{• Reincidentes $\quad$ Primários}

Fonte: Elaboração própria.

Observa-se então que dentre os questionados cerca de $71 \%$ já cumpriu medida socioeducativa de privação de liberdade, seja em qualquer instituição, no período máximo referente a 3 anos e mínimo referente a 6 meses.

Em relação ao construto culpabilidade observou-se nos entrevistados aproximadamente um nível de 3,12 uma pontuação média-alta em uma escala que varia de 1, grau mínimo de culpa, e 5, grau máximo de culpa. Os escores totais em relação a distribuição de frequência foram elevados de tal forma que não se convém a comparação entre variáveis e sentimento de culpa, uma vez que a diferença obtida seria mínima e de pouca representatividade e utilidade paralela.

\section{Discussões}

A partir dos resultados é então de grande aplicabilidade, reflexões e análises críticas comparativas com a literatura já existente. Observa-se deste modo, que a quantificação corrobora com a literatura disposta, cuja atitude do ato infracional é vista como derivada da má distribuição de educação adequada para com todas as classes sociais.

Desta forma apresenta Muniz (2006) quando define como irresponsabilidade do estado não atentar a suas obrigações como fonte de educação, mas sim buscar remediar os atingidos através de punições severas. Assim, ainda destaca Lucena (2015) fincando a conceituação de que a educação é, sem alternativas, indispensável para um desenvolvimento saudável, ainda se nota o quão a perspectiva e a ação educacional são necessárias visto que abrangem um leque de possibilidades que distanciam o jovem da criminalidade e do envolvimento com drogas e a outros desvios em geral.

Não obstante, nota-se além do mais a ineficácia do sistema de reeducação no complexo privativo investigado no cumprimento dos direitos ressaltados no artigo 121 do ECA, uma vez que muitos, mesmo que em longa permanência, não gozem dos direitos educacionais Ihes concedidos teoricamente, e assim permanecem estagnados em uma mesma situação levando-os a diversas internações consecutivas. 
Outro dado que corresponde a literatura disponível e o quesito reincidência. Observa-se deste modo que, mesmo cumprindo a medida completa, sendo liberado ou trocando de medida legalmente o jovem não encontra de outros meios e acaba por retornar a instituições. Os dados comprovaram que $71 \%$ dos adolescentes entrevistados já cumpriram medida de privação de liberdade na mesma ou em outras instituições, tal dado comprova o fracasso do estado em relação a ressocialização desses jovens assim como Sá (2009) afirma, por mais que se negue o caráter punitivo e se reforce a perpetuação do contexto educativo, na prática os polos se invertem.

No que se refere então ao construto sentimento de culpa e culpabilidade abarca-se uma série de observações. $O$ dado coletado e analisado estatisticamente indica que em média os entrevistados apresentam 3,12 em um nível cujo máximo é 5,0 . As respostas abrangem que vão desde reconhecimento do erro e desejo de voltar atrás até necessidade de reparar o dano e reprimir vontades errôneas. Atenta-se, porém para a imprecisa interferência de eventos de desejabilidade social que guiariam os entrevistados a apontarem alternativas que admitissem bons julgamentos e aceitação (HOLTGRAVES, 2017).

Admitindo-se influencia mínima da desejabilidade social percebe-se que na literatura correspondente encontram-se uma série de divergências em relação ao construto avaliado, segundo Segundo Bock; Furtçado; Teixeira (2001) o resultado encontrado seria oposto uma vez que em seus trabalhos traz a precariedade do sentimento de culpa nesses jovens, por absterem-se de figuras autoritárias. Ainda, Kohlberg 1969 (apud KOLLER; BERNARDES, 1997) afirma que esse sentimento é mais dificultoso a esses jovens por não compreenderem uma perspectiva empática por completo, e mais uma vez a afirmação é refutada pelos resultados apresentados os quais superaram as expectativas obtendo um escore relativamente acima da pontuação média.

\section{Considerações Finais}

A partir do que foi exposto pode-se notar a consistência dos dados demográficos em relação aos já existentes na literatura, mostrando assim um alto índice de reincidência e uma baixa escolaridade em relação a comunidade de adolescentes em conflito com a lei. Todavia, não somente houveram concordâncias com a revisão realizada as perspectivas em relação a culpabilidade se mostraram inconsistentes quando comparados com os dados estatisticamente coletados.

Teoricamente o sentimento de culpa serviria como autopunitivo e implicaria na baixa da taxa de comportamento inadequado, contudo, obtevese a segunda análise, a resposta obtém influencia momentânea do contexto da internação. Durante as reflexões e arrependimentos o jovem apresentaria culpa e remorso, todavia na mudança brusca de contexto, já partindo para liberdade, a ineficácia da reeducação e reinserção social abarcaria no retorno a visão primária causando assim a reincidência e o recomeço do ciclo: infração, punição, remorso e novamente infração. 
Entende-se assim como uma boa asserção a utilização de recursos mais sólidos que não só proporcionem a perpetuação dos sentimentos de remorso, mas também incorpore alternativas para evitar a reincidência e a recaída ao ato infracional. Sentir-se culpado não basta, deve-se propor sentimentos de amparo e cuidado para que este jovem se sinta confortável ao voltar as ruas e recomeçar.

No entanto, deixa-se exposto aqui as limitações do estudo referentes a amostra de local único e a influência inexata da desejabilidade social, fenômeno que afeta as pesquisas de auto relato em função do julgamento e da aceitabilidade social pretendida. Por fim acredita-se que seja de grande valia a perpetuação do conhecimento acerca do tema, bem como questões relacionada como a inter-relação entre a família e o desenvolvimento moral do sentimento de culpa nesses jovens, além de levantamentos acerca de reinserções e a continuidade da culpabilidade aqui constada.

\section{Referências}

AQUINO, Thiago Antônio Avellar; MEDEIROS, Bruno. Escala de culpabilidade:

Construção e validação de construto. Aval. Psicol. Porto Alegre: vol.8, n.1, 2009.

BRASIL, Estatuto da criança e do adolescente: Lei federal n 8069, de 13 de julho de 1990. Rio de Janeiro: Imprensa Oficial, 2002.

CAMPOS, D. M. S. - Psicologia da Aprendizagem, 19² ed., Petrópolis: Vozes, 1986.

FEIJÓ, Maria Cristina; ASSIS, Simone Gonçalves. O contexto de exclusão e de vulnerabilidade de jovens infratores e de suas famílias. Estudos de Psicologia, Natal, v. 9, n. 1, 2004.

GUILHARDI, Hélio José. Análise comportamental do sentimento de culpa. Ciência do comportamento: conhecer e avançar, 2002.

HOLTGRAVES, Thomas. Social Desirability and the Interpretation of Uncertainty Terms in Self-Report Questions. Applied Cognitive Psychology, v. 31, n. 6, 2017.

IRWIN, Charles E.; MILLSTEIN, Susan G. Biopsychosocial correlates of risk-taking behaviors during adolescence: Can the physician intervene?. Journal of Adolescent Health Care, 1986.

KOLLER, Silvia Helena; BERNARDES, Nara M G. Desenvolvimento moral pró- social: semelhanças e diferenças entre os modelos teóricos de Eisenberg e Kohlberg. 1997

LAPSLEY, Daniel K.; STEY, Paul C. Id, Ego, and Superego. Encyclopedia of Human Behavior, 2nd Edition. Ramachandran VS (ed): Elsevier, 2011.

LASKOSKI, Lorena Maria; NATIVIDADE, Jean Carlos; HUTZ, Claudio Simon. Development of Instruments to Assess Shame and Guilt in Adolescents: Empirical Differences Between the Constructs. Ribeirão Preto, 2013.

LIMA, Felipe Fernandes et al. Evidências de validade para as escalas de culpa e vergonha em uma amostra de estudantes universitários. Encontro: Revista de Psicologia, v. 16, n. 25, 2015.

LUCENA, Elis Formiga. Desenvolvimento e criminalidade: Um estudo do perfil de adolescentes em conflito com a lei penal internos no lar do garoto-pb. Campina Grande-PB, 2015.

MINISTÉRIO DA SAÚDE (BR); CONSELHO NACIONAL DE SAÚDE. Resolução nº 466, de 12 de dezembro de 2012. Diretrizes e normas regulamentadoras de pesquisas envolvendo seres humanos. Diário Oficial da União [da] República Federativa do Brasil, v. 150, n. 112, 2013.

MUNIZ, Adriano Sampáio. $\mathbf{O}$ adolescente infator. Universidade Federal de Santa Catarina, 2009,

PROENÇA, Cátia Sofia Reis. Práticas educativas parentais e comportamentos de risco na adolescência. 2018. Tese de Doutorado. 
NÍVEL DE CULPABILIDADE EM ADOLESCENTES EM CONFLITO COM A LEI

SÁ, Arthur Luiz Carvalho. As medidas socioeducativas do ECA e a reincidência da delinquência juvenil. 2009. 71 f. Monografia (Graduação) - Curso de Direito, Centro Universitário do Distrito Federal, Brasília, 2009.

SHAUGHNESSY, John J.; ZECHMEISTER, Eugene B.; ZECHMEISTER, Jeanne S. Metodologia de pesquisa em psicologia. AMGH Editora, 2012.

SANTOS, Andreia da Silva. Diferenças individuais na tendência para a vergonha e culpa: antecedentes motivacionais.2009. 100 f. Tese (Doutorado) - Curso de Psicologia, Universidade de Lisboa, Lisboa, 2009.

WINNICOTT, Donald W. Psicanálise do sentimento de culpa. O ambiente e os processos de maturação: estudos sobre a teoria do desenvolvimento emocional. Porto Alegre: Artmed, 1983 